\title{
Research on the Problems and Countermeasures of the Supply Side Reform of Domestic Rural Tourism
}

\author{
Qiuhong Yang
}

China West Normal University, Sichuan, Nanchong, 637000

Keywords: Supply Side Reform, Domestic Rural Tourism, Problems and Countermeasures

\begin{abstract}
At present, there are some problems in the rural tourism supply side, for example, the subjectivity of rural tourism supply side is unknown, many rural tourism projects are out of the vision of farmers' richness, the inefficient excavation of the rural tourism resources; Rural tourism supplies too much invalid products, the project profitability is limited, the phenomenon of widespread loss; rural tourism supply side of the capital elements of high funding risk. In response to these problems, the paper proposes to release the enthusiasm and creativity of farmers in rural tourism, deeply excavate the natural and cultural connotation of rural areas and preserve the rural nature, reduce the invalid supply of rural tourism products, conscientiously do a good job of preliminary investigation and fully understand the risks and difficulties.
\end{abstract}

\section{Introduction}

Rural tourism combines multiple attributes such as economy, culture, ecology and service. It plays a key role in solving the problems concerning agriculture, rural areas and farmers, coordinating the economic and social development in urban and rural areas, meeting the spiritual and cultural needs of people, protecting the ecology, adjusting the structure and expanding domestic demand With its unique and important role, especially in the current economic growth is facing downward pressure, the new economic growth point to be found in the background, more broad prospects for development. In 2015, the number of tourists in leisure agriculture and rural tourism in the country exceeded 2.2 billion, an increase of nearly 8 times that of 2007; the tourism revenue of 440 billion yuan increased nearly 11 times over 2007. However, the rapid development of rural tourism with the theme of sightseeing and picking in our country for more than 30 years is mainly dominated by extensive (extension), scale (quantity), government and factor-driven, while neglecting the transition to intensive Type), efficiency (quality), innovation-driven transformation and upgrading, the problems brought about by the rural tourism products are invalid over-supply, while the effective supply is insufficient. Effective supply refers to the total supply and supply structure that can meet the needs of consumers to the maximum, on the contrary, it is an invalid supply. The phenomenon of "supply and demand mismatch" or "supply not needed" brought by effective supply and inefficient supply is widespread in rural tourism, resulting in the rural tourism everywhere. However, the escalating tourist consumption demand of the public Strange phenomenon that can not be satisfied. Therefore, we must clearly recognize that the main reason for restricting the development of rural tourism is not the lack of effective demand, but the supply side of the effective supply and inefficient supply of too much. The supply side structure of rural tourism must be reformed. The supply side structure of rural tourism is composed of elements such as community farmers, developers, managers, rural resources, capital and policy system. By excavating the potential of rural tourism supply side elements, optimizing the allocation of elements to reduce ineffective and low-end supply, expanding effective and high-end supply. Thus improving the quality and efficiency of rural tourism supply as a whole [1].

\section{Rural tourism supply-side resource elements}

The rural area is the geography of rural residents' production and living. It is a concrete concept. However, the "village" in rural tourism is a multi-connotative and imaginative abstract concept. No 
matter what the different connotations of rural tourism are, rural character is the essential feature of academic identity and emphasis. Tao Yuxia believes that rural areas have a triple "root" image. First, the countryside is the root of life. Land is the source of life and the basis of existence. It imparts all things to life. Although people bear the burden of life, people still "poetically inhabit this land." Returning to the native land and returning to nature are the natural demands of human nature. Second, the countryside is the root of traditional culture. The Chinese nation once had a long, rich and splendid agricultural civilization. Based on agricultural civilization, it formed a vast and profound traditional culture [2]. Excellent traditional culture is the spiritual lifeline of a nation. It is also the foundation of a national heritage and development. The Chinese excellent traditional culture Once made an indelible and significant contribution to the progress of human civilization, the traditional culture of our country has been diminished by the impact of the modern industrial civilization in the West. More and more historical and cultural markings of the same strain have been preserved in the villages of Anhui, Shanxi and Fujian. Therefore, rural tourism is an effective carrier for understanding, approaching, inheriting and innovating excellent traditional culture and is the root of our culture. Third, the country is the poetic root. "Withered old tree faint crows, small bridges flowing people" "Picking the East Ju Lei, leisurely see the Nanshan" "far on the Hanshan stone path oblique, Baiyun students at home," an area of ink village, pastoral idol is our Spiritual home, poetic habitat, but also the realm of harmony between man and nature. On the other hand, people in modern cities generally feel cramped space, time constraints, depression, breathing difficulties, environmental pollution and interpersonal complications. In this way, the "gravity" of the village and the "thrust" of the city inspire the "rural image" formed by the integration of the rural areas, the nostalgia, the rural vows and the township dreams in the hearts of urban tourists this is the original motive for traveling to rural areas.

\section{Rural tourism supply-side reform measures}

Tourism development to this stage and level today, the traditional way to capture the spot attractions tourist attractions can not adapt to the needs of the development of modern tourism, we can no longer stay in the scenic spots alone meal, by ticket Economic dinner, relying on resources to eat, rely on our ancestors to eat at the level, can no longer stay in the limited development of scenic spots, closed the door to engage in tourism on the old road, we must accelerate the realization of the tourism from the tourist spots to the transition? . Global tourism is a system of spatial panorama of tourism, is different from the traditional tourism of modern tourism, different from small tourism, tourism, representing the new direction of the development of modern tourism, in line with the common development of the world tourism development The law and overall trend are a profound change in the process of tourism development. We want to make global tourism an overall strategy for the development of tourism in the province in the era of mass tourism. According to the requirements of globalization, we should allocate tourism resources, plan the layout of tourism, promote the construction of scenic spots, strengthen the administration of law enforcement, and integrate the development of industries. A region as a whole as a fully functional tourist destination to build operations and management, to achieve the integration of scenic spots inside and outside, so that everywhere is a tourist attraction, everyone is a tourist image. Therefore, we should use reform methods to promote the structural adjustment and optimization of rural tourism supply and to promote the supply-side reform of rural tourism. We should start from the supply side, adjust and optimize the rural tourism structure by means of reform, pay more attention to system innovation and technology Drive and take the road of modern rural tourism with high output, product safety, resource saving and environment-friendly, so as to realize global tourism. The intelligent and satisfied full-service is the invisible support for the sustained and healthy development of rural tourism and the soft power for optimizing the supply structure of rural tourism, which is an important means to realize the tourism in the whole world. First, to build and improve the Huananan Smart Tourism Cloud centered on tourism public information services, industry management and e-commerce, and to create a platform that includes travel product promotion, personalized service booking, product pre-sale and settlement, real-time Tourist information query, travel vehicle 
scheduling, explain the navigation, capacity monitoring and other online and offline combination one-stop "travel service" platform to achieve where tourists travel and tourism services to cover where to reach Smart travel management and service. Second, to provide standardized and personalized combination of rural tourism services. In the rural tourism services Shu appropriate, convenience, humanity, etc. to develop appropriate standards and standardize the basic services. For service methods, methods and opportunities can provide personalized service due to different innovations in time, place and subject to improve the satisfaction of tourists. Thirdly, we should actively explore ways of diversifying incomes of villagers in such rural tourism as land, housing stocks and employment of children. Therefore, peasants, foreign operators and enterprises can participate equitably, make profits on an equal basis and all stakeholders have the right to be assigned. Therefore, they can provide the most enthusiastic service and the tourists' satisfaction will also be higher [3].

In this regard, increase the development and utilization of rural tourism resources, shaping the rural tourism brand is particularly important, and imminent.

Rural tourism enterprises should operate with integrity and innovate under the rules of the industry, improve the reputation of rural tourism enterprises among citizens, and attract citizens to choose rural tourism enterprises for consumption. To continuously improve business management level, it is necessary to face the majority of consumer groups and society with a healthy and good image, and to strengthen the training of practitioners and business skills. It can also carry out brand chain and cooperation with star-rated hotels and mature travel companies At the same time, we should give play to the advantages of the rural areas and develop experimental demonstration bases for all disciplines and comprehensive experimental education bases. We can also join hands with universities and research institutes to achieve such functions as education and scientific research. Pay attention to project design in the construction of rural tourism enterprises. Clearly designed themes, distinct functional areas, planning landscape with infrastructure and infrastructure; to carefully select the business project to study market demand, planning business model. To highlight the corporate culture shaping. Farming culture and local customs are the core elements and are the central goal of rural tourism to have lasting vitality. Therefore, the development of rural tourism should be based on the advantages of its own resources. We should fully discover and tap the uniqueness and superiority of local resources and establish a tourism brand that suits our own development. For example, the flora and fauna involved in rural tourism are rich in cultural connotations such as history, economy, science, spirituality, folk customs and literature, various folk tales, stories, allusions, various literary works such as essays, In mind, poetry and funeral should be properly planned into business projects to enhance business taste. We should pay attention to the rationality and feasibility of publicity. We can make full use of various festivals and holidays in rural areas, and promote public impression and influence through various promotional media, organizing sightseeing tours, popular science training, and organizing activities. And continue to explore new ways to take the surrounding area with the formal tourist attractions combined to expand the jurisdiction of the surface area, the formation of rural tourism industry area, to enhance the visibility of rural tourism attractions in order to attract and attract more consumers, Expand the market for rural tourism. To achieve global tourism, we must innovate the tourism industry. Improve the rural tourism industrial chain, should improve and strengthen industrial chain at both ends of the industry before and after, excluding rural tourism is only accommodation, scenic spots, catering thinking. Innovative tourism products, and actively cultivate a new tourism industry format, build a new carrier of development. Promote the tourism town, tourism scenic road, tourist greenway, tourist resort, tourism industry cluster, special tourism base, research tourism base, pension tourism base and other emerging tourism formats and product construction. We will energetically cultivate and support new rural tourism formats represented by leisure and tourism, village holidays, ancient villages and villages, and promote the construction of destinations such as featured touring destinations, national recreation areas, and leisure and tourism demonstration cities. Promote tourism + new lifestyles way, including tourism + research (education), tourism + transportation, tourism + leisure, tourism + new pension, tourism + health, tourism + shopping, etc., 
vigorously cultivate new tourism in the whole world New product format. To speed up the special extraction of color, in creating a boutique travel brand work hard. Give full play to the advantages of natural and human resources in the region and create a regional brand [4].

\section{Conclusions}

Rural tourism in the three kinds of risk of natural risks, management and risk of the ultimate conduction, conversion and performance for the financial risk. Earnestly do a good job in early research, fully understand the risks and difficulties, enhance risk awareness, strengthen risk management, actively participate in agricultural insurance, or take technical outsourcing and other professional people to do professional things is to circumvent and reduce the risk of rural tourism funds effectively way [5].

\section{Acknowledgements}

The project source: the university-level research projects of China west normal university (rural tourism research based on the agricultural supply-side reform --- take Sichuan province for example) the project number: 416492

\section{References}

[1] Liao Junhua, Li Yingying. Supply-side reform to promote the transformation and upgrading of rural tourism [J]. World Agriculture. 2016 (10):18 21.

[2] Zhu Honggen. Discussion on the relationship between rural tourism supply side reform and new rural construction [J]. Modern Commerce and Industry. 2016 (26) :209 213.

[3] Zhang Hui, Yue Yanxiang. Rational thinking of global tourism [J]. Journal of Tourism. 2016 (09) 66 67.

[4] Dai Xuefeng. Global Tourism: Tourism to lead the important means to deepen the reform [J]. 2016:11 15.

[5] Yang Tian, Hu Yong-hong. Research on the Development Strategy of Tourism in Xuchang City under the Guidance of Global Tourism [J]. Huazhong Architecture. 2016 (08) :82 85. 